\title{
High-intensity versus low-intensity non-invasive ventilation in patients with stable hypercapnic COPD: a randomised crossover trial
}

\author{
Michael Dreher, ${ }^{1}$ Jan H Storre, ${ }^{1}$ Claudia Schmoor, ${ }^{2}$ Wolfram Windisch ${ }^{1}$
}

${ }^{1}$ Department of Pneumology, University Medical Hospital, Freiburg, Germany ${ }^{2}$ Clinical Trials Center, University Medical Center, Freiburg, Germany

\section{Correspondence to Prof Dr Wolfram Windisch, Department of Pneumology, University Hospital Freiburg, Killianstrasse 5, D-79106 Freiburg, Germany; wolfram. windisch@uniklinik-freiburg.de}

Registration number: UKF001909

$\mathrm{MD}$ and JHS contributed equally to this work.

Received 25 July 2009 Accepted 30 November 2009

\begin{abstract}
Rationale The conventional approach of low-intensity non-invasive positive pressure ventilation (NPPV) produces only minimal physiological and clinical benefits in patients with stable hypercapnic chronic obstructive pulmonary disease (COPD).

Objectives To determine whether the novel approach of high-intensity NPPV is superior to low-intensity NPPV in controlling nocturnal hypoventilation.

Methods A randomised controlled crossover trial comparing 6 weeks of high-intensity NPPV (using controlled ventilation with mean inspiratory pressures of $28.6 \pm 1.9 \mathrm{mbar}$ ) with low-intensity NPPV (using assisted ventilation with mean inspiratory pressures of $14.6 \pm 0.8 \mathrm{mbar}$ ) was performed in 17 patients with severe stable hypercapnic COPD.
\end{abstract}

Results Two patients refused low-intensity NPPV and two patients dropped out while on low-intensity NPPV. Thirteen patients (mean forced expiratory volume in $1 \mathrm{~s}$ $\left(\mathrm{FEV}_{1}\right) 0.76 \pm 0.29$ I) completed the trial. High-intensity NPPV produced higher pneumotachographicallymeasured expiratory volumes, with a mean treatment effect of $96 \mathrm{ml}$ (95\% Cl 23 to 169) ( $p=0.015)$. This resulted in a mean treatment effect on nocturnal arterial carbon dioxide tension $\left(\mathrm{Paco}_{2}\right)$ of $-9.2 \mathrm{~mm} \mathrm{Hg}(95 \% \mathrm{Cl}$ -13.7 to -4.6$)(p=0.001)$ in favour of high-intensity NPPV. Daily use of NPPV was increased in high-intensity NPPV compared with low-intensity NPPV, with a mean difference of $3.6 \mathrm{~h} /$ day $(95 \% \mathrm{Cl} 0.6$ to 6.7$)(p=0.024)$. In addition, compared with baseline, only high-intensity NPPV resulted in significant improvements in exerciserelated dyspnoea, daytime $\mathrm{PaCO}_{2}, \mathrm{FEV}_{1}$, vital capacity and the Severe Respiratory Insufficiency Questionnaire Summary Score.

Conclusions High-intensity NPPV is better tolerated by patients with severe chronic hypercapnic COPD and has been shown to be superior to the conventional and widely-used form of low-intensity NPPV in controlling nocturnal hypoventilation. High-intensity NPPV therefore offers a new promising therapeutic option for these patients.

\section{INTRODUCTION}

Among the potentially beneficial treatment options for chronic hypercapnic respiratory failure (HRF) arising from chronic obstructive pulmonary disease (COPD), non-invasive positive pressure ventilation (NPPV) remains under question because of a lack of convincing evidence in the literature. Although the most recent randomised controlled trial (RCT) concluded that adding nocturnal NPPV as a supplement to long-term oxygen therapy (LTOT) may improve survival of COPD patients with chronic
HRF, this improvement was small and quality of life was reportedly impaired. ${ }^{1}$ In addition, two previous RCTs found that LTOT supplemented with longterm NPPV was no more beneficial to survival than LTOT alone. ${ }^{2}{ }^{3}$ Furthermore, a meta-analysis of four RCTs clearly showed that NPPV failed to improve lung function, gas exchange and sleep efficiency, ${ }^{4}$ while the most recent systematic review also concluded that RCTs did not find an improvement in gas exchange following NPPV in patients with COPD. ${ }^{5}$ However, it has been argued that the inspiratory positive airway pressures (IPAP) used in the RCTs and ranging on average between 10 and $18 \mathrm{~cm} \mathrm{H}_{2} \mathrm{O}$ were too low to successfully lower the raised levels of arterial carbon dioxide tension $\left(\mathrm{PacO}_{2}\right)$, thus providing an alternative explanation as to why NPPV has hitherto failed to improve outcome ${ }^{5-8}$ although NPPV using IPAP values of $18 \mathrm{~cm} \mathrm{H}_{2} \mathrm{O}$ showed some effect on alveolar ventilation. ${ }^{9} 10$

Furthermore, there are several non-randomised trials which used controlled forms of NPPV, with considerably higher IPAP levels of approximately $30 \mathrm{~cm} \mathrm{H}_{2} \mathrm{O}$ aimed at maximally decreasing raised $\mathrm{PacO}_{2}$ levels. Thereby, improvements in blood gases, lung function, breathing pattern, kachexia and health-related quality of life (HROL) have been demonstrated. ${ }^{611-15}$ This form of NPPV has recently been labelled as highintensity NPPV (HI-NPPV) ${ }^{\gamma} 16$ and clearly contrasts with low-intensity NPPV (LI-NPPV), the abovementioned technique which was not associated with any consistent improvement in blood gases and outcome. However, the different types of NPPV have not yet been comparably assessed using an RCT.

In particular, the hypothesis that HI-NPPV is superior to LI-NPPV needs further investigation. The present study therefore aimed to compare the physiological effects of HI-NPPV and LI-NPPV in a randomised crossover study. It was hypothesised that HI-NPPV significantly augments nocturnal alveolar ventilation and, as a consequence, is superior to LI-NPPV in improving raised overnight $\mathrm{PaCO}_{2}$ levels. In addition, we tested whether the hypothesised initial benefits of HI-NPPV lead to further substantial improvements in important clinical parameters including lung function, exercise capacity, dyspnoea, treatment compliance and HROL. In the event of such a positive outcome, RCTs investigating the long-term effect of HI-NPPV on survival would definitely be warranted.

\section{METHODS \\ Patients}

Patients with chronic HRF (daytime $\mathrm{PaCO}_{2}$ $>45 \mathrm{~mm} \mathrm{Hg}$ and nocturnal $\mathrm{PacO}_{2}>50 \mathrm{~mm} \mathrm{Hg}$ ) 
due to COPD (grade IV according to GOLD criteria ${ }^{17}$ ) were consecutively enrolled. All patients received appropriate medical therapy in addition to LTOT according to GOLD guidelines, ${ }^{18}$ and this treatment was maintained throughout the study. All patients included in the study were electively established on NPPV during a stable phase of their disease. Patients were not included in the study if they had acute respiratory failure (with two of the following criteria: increasing cough, purulent sputum, elevated leucocytes or C-reactive protein $>5 \mathrm{mg} / \mathrm{dl}$, pulmonary infiltrates on chest x-ray, need for antibiotic treatment), received invasive ventilation via a tracheostomy, were weaned from invasive ventilation, were intubated during the last 3 months or received any other form of ventilatory support prior to the study, including continuous positive airway pressure. Further exclusion criteria were bronchiectasis, post-tuberculosis sequelae, rib cage deformities, neuromuscular disorders, bronchial carcinoma and clinical evidence of severe obstructive sleep apnoea (snoring, reported apnoeas).

\section{Measurements}

Lung function parameters (Masterlab-Compact Labor, Jaeger, Hochberg, Germany) were assessed in accordance with international guidelines. ${ }^{19}$ Peak maximal inspiratory mouth occlusion pressures (PImax) (ZAN ${ }^{100}$, ZAN Gerätetechnik GmbH, Oberthulba, Germany) were measured as previously described. ${ }^{20}$ Arterial blood gases ( $A B G$ ) were taken from the arterialised earlobe (AVL OMNI, Roche Diagnostics GmbH, Graz, Austria) with and without NPPV. Supplemental oxygen was applied for both instances. Exercise capacity was assessed by a standardised 6-minute walking test (6MWT). ${ }^{21}{ }^{22}$ Dyspnoea during the walking test was assessed by the Borg dyspnoea scale (BDS). ${ }^{23}$ HROL was assessed using the Severe Respiratory Insufficiency Questionnaire (SRI), which specifically targets the sphere of patients with COPD with chronic HRF who are receiving longterm NPPV. ${ }^{24} 25$ For ventilation measurements, a pneumotachograph (Ventrak Respiratory Monitoring System, model 1550; Novametrix Medical Systems, Wallingford, Connecticut, USA) was placed between the mask and the exhalation port as previously described. ${ }^{26} 27$ Compliance with NPPV was assessed by the ventilator counter reading. Finally, the number of days needed for NPPV commencement was recorded.

\section{Study design}

The study had a randomised, open-label, two-treatment, twoperiod crossover design. Investigators were not blinded. Patients were randomised to receive either the sequence HI-NPPV/LINPPV or the sequence LI-NPPV/HI-NPPV. After successful commencement of NPPV in the first period, patients were discharged and then readmitted after 6 weeks of home mechanical ventilation. In the second period, patients were switched to the complementary mode of NPPV and then discharged, when they once again performed NPPV at home for 6 weeks prior to final readmission. The study was performed as a single-centre study at the Department of Pneumology, University Hospital Freiburg, Germany.

Daytime measurements (lung function parameters, PImax, 6MWT, HROL, ABG during spontaneous breathing receiving oxygen) and nocturnal measurements while receiving NPPV (only at follow-up visits) in addition to supplemental oxygen (ABG at $01.00 \mathrm{~h}$ and $04.00 \mathrm{~h}$ and pneumotachographic measurements) were performed at baseline and during the two follow-up visits in hospital.

\section{Techniques of non-invasive positive pressure ventilation}

Pressure-limited NPPV with passive humidification using a heat and moisture exchanger (Hygrovent S, Medisize bv, Hillegom,
The Netherlands) if needed according to tolerance and supplemental oxygen was used in all patients for both treatment arms. The BREAS VIVO 40 (Breas Medical AB, Molnlycke, Sweden) or a modified Smart Air (Airox, Pau Cedex, France), with both ventilators allowing the IPAP to be increased up to 40 mbar, was used. For HI-NPPV the assist/control mode was chosen. Thus, HI-NPPV was aimed at maximally decreasing $\mathrm{Paco}_{2}$ by stepwise increases in IPAP and respiratory rate beyond the spontaneous breathing frequency to establish controlled ventilation as described in detail elsewhere. ${ }^{7}$ For LI-NPPV, pressure support ventilation with IPAP ranging between 14 and 16 mbar and backup respiratory rates of 8 breaths/min were used as in previous studies. $^{3} 4$

The inspiratory/expiratory ratio was set to $1: 2$ for assist/ control NPPV (HI-NPPV), but could be modified according to patients' tolerance. The quickest pressure rise was chosen for all patients and both modes. The inspiratory flow trigger was set to 3 1/min for both HI-NPPV and LI-NPPV. For LI-NPPV the expiratory trigger was set to $70 \%$ of maximal inspiratory flow. Commercially available nasal or nasal-mouth masks were used for NPPV according to the best tolerance.

\section{Predetermination of study endpoints}

The primary endpoint was $\mathrm{PacO}_{2}$ during nocturnal NPPV, determined as the mean value of the measurements at $01.00 \mathrm{~h}$ and $04.00 \mathrm{~h}$. Secondary endpoints were daytime $\mathrm{PaCO}_{2}$ and $\mathrm{HCO}_{3}{ }^{-}$, lung function, PImax, BDS after 6MWT, 6MWD and SRI scales. In addition, compliance with NPPV and days needed for NPPV commencement were assessed.

\section{Statistical analysis}

Sample size calculation was based on the primary endpoint, which was $\mathrm{PacO}_{2}$ during nocturnal NPPV. The study was designed to show a difference in nocturnal $\mathrm{PacO}_{2}$ of $8 \mathrm{~mm} \mathrm{Hg}$ between LI-NPPV and HI-NPPV. A SD in the difference of $8 \mathrm{~mm}$ $\mathrm{Hg}$ was assumed according to previous findings. ${ }^{6}$ To show this difference in a crossover design with a two-sided significance level of 0.05 and a power of 0.90 , the recruitment of 13 patients was required.

The comparison of LI-NPPV and HI-NPPV in the crossover setting was performed in the full analysis set, which included all randomised patients who received both treatments. Outcome measurements were tested for normality using the Kolmogorov-Smirnov test, and no departure from normality was detected. An analysis of variance (ANOVA) model was used with "treatment", "period" and "randomised sequence" defined as fixed effects and "patient within sequence" defined as a random effect. The treatment effect was estimated with a 95\% CI and tested with a two-sided level of 0.05 . In addition, tests for period effects and for carryover effects (ie, treatment-period interactions) were performed. Treatment result and baseline measurement were compared by calculating the mean difference with $95 \% \mathrm{CI}$ and performing a paired $t$ test separately for LI-NPPV and HI-NPPV for all patients who received the respective treatment.

\section{RESULTS}

Seventeen patients were consecutively enrolled in the study, four of whom dropped out (figure 1). In the first period, one patient refused LI-NPPV in hospital due to intolerance and another patient stopped LI-NPPV at home despite successful establishment in hospital. After the first period, two patients refused to switch from HI-NPPV to LI-NPPV because of increasing dyspnoea and fear of asphyxia during commencement of LI-NPPV. These two patients continued HI-NPPV at home. Ventilator 
settings and pneumotachographic measurements of actual ventilation for the 13 patients (mean \pm SD forced expiratory volume in $1 \mathrm{~s}\left(\mathrm{FEV}_{1}\right) 0.76 \pm 0.291$, 4 women, $\left.9 \mathrm{men}\right)$ in the full analysis set are shown in table 1.

Seven patients used a nasal mask, six patients used a nasalmouth mask and two patients received passive humidification without any changes throughout the study. Upon entry into the study, the mean $\mathrm{pH}$ was $7.39 \pm 0.04$ and the mean BMI was $24.1 \pm 5.7 \mathrm{~kg} / \mathrm{m}^{2}$.

Overall, while HI-NPPV resulted in significantly higher inspiratory and expiratory volumes, leak volumes were also increased (table 1). In addition, the measured peak inspiratory pressure was significantly higher during HI-NPPV than during LINPPV (table 1). Interestingly, although the respiratory rates set by the ventilator differed considerably between HI- and LI-NPPV, the actual respiratory rates measured pneumotachographically were nearly identical (table 1). Treatment compliance was higher with HI-NPPV than with LI-NPPV, but more days in hospital were needed to establish patients on HI-NPPV (table 1).

Nocturnal $\mathrm{PacO}_{2}$ decreased more with HI-NPPV: the mean treatment effect on $\mathrm{PacO}_{2}$ in LI-NPPV versus $\mathrm{HI}-\mathrm{NPPV}$ was $-9.2 \mathrm{~mm} \mathrm{Hg}(95 \% \mathrm{CI}-14.8$ to -3.6$)(\mathrm{p}=0.004)$ at $01.00 \mathrm{~h}$ and $-9.2 \mathrm{~mm} \mathrm{Hg}(95 \% \mathrm{CI}(-12.8$ to -5.6$)(\mathrm{p}=0.0002)$ at $04.00 \mathrm{~h}$. The results for mean nocturnal $\mathrm{PacO}_{2}$ are shown in table 2 and figure 2 .

Since all patients received supplemental oxygen, no difference in mean arterial oxygen tension $\left(\mathrm{PaO}_{2}\right)$ was observed in any of the comparisons. There was also a significant treatment effect for $\mathrm{HCO}_{3}{ }^{-}$and the BDS following walking as well as a trend towards improved lung function (table 2). However, changes in $\mathrm{FEV}_{1}$ seemed to differ over the study period (test for treatment-period interaction, $\mathrm{p}=0.18$ ), while patients in treatment sequence HI-NPPV/LI-NPPV had slightly higher baseline $\mathrm{FEV}_{1}$ values $(0.84 \pm 0.33 \mathrm{ml})$ than patients in treatment sequence LINPPV/HI-NPPV $(0.66 \pm 0.22 \mathrm{ml})$.

Table 1 Ventilator settings, pneumotachographic measurements of ventilation parameters, treatment compliance and days in hospital needed for NPPV acclimatisation: high-intensity versus low-intensity NPPV

\begin{tabular}{|c|c|c|c|c|c|}
\hline & Period & LI-NPPV & HI-NPPV & $\begin{array}{l}\text { Difference between } \\
\text { treatments }(95 \% \mathrm{CI})\end{array}$ & $\begin{array}{l}\mathbf{p} \\
\text { Value }\end{array}$ \\
\hline IPAP (mbar) & & $14.6 \pm 0.8$ & $28.6 \pm 1.9$ & & \\
\hline EPAP (mbar) & & $4.0 \pm 0$ & $4.5 \pm 0.7$ & & \\
\hline $\mathrm{Bf}(/ \mathrm{min})$ & & $8.0 \pm 0$ & $17.5 \pm 2.1$ & & \\
\hline $\begin{array}{l}\text { Supplemental oxygen } \\
(1 / \mathrm{min})\end{array}$ & & $2.2 \pm 0.8$ & $2.2 \pm 0.8$ & & \\
\hline \multirow[t]{2}{*}{ Vinsp (ml) } & Period 1 & $821 \pm 257$ & $1183 \pm 486$ & 325 (159 to 492$)$ & 0.00 \\
\hline & Period 2 & $846 \pm 356$ & $1195 \pm 213$ & & \\
\hline \multirow[t]{2}{*}{ Vexp (ml) } & Period 1 & $351 \pm 161$ & $414 \pm 218$ & 96 (23 to 169$)$ & 0.01 \\
\hline & Period 2 & $289 \pm 130$ & $415 \pm 169$ & & \\
\hline \multirow[t]{2}{*}{ Vleak (ml) } & Period 1 & $469 \pm 336$ & $769 \pm 674$ & 226 (928 to 425$)$ & 0.030 \\
\hline & Period 2 & $557 \pm 470$ & $780 \pm 317$ & & \\
\hline \multirow[t]{2}{*}{$\mathrm{RR}(/ \mathrm{min})$} & Period 1 & $15.4 \pm 3.5$ & $17.8 \pm 3.7$ & $-0.5(-3.4$ to 2.4$)$ & 0.71 \\
\hline & Period 2 & $18.9 \pm 5.1$ & $15.3 \pm 1.3$ & & \\
\hline \multirow[t]{2}{*}{ PIP (mbar) } & Period 1 & $11.4 \pm 2.6$ & $23.8 \pm 4.8$ & 11.9 (9.5 to 14.3$)$ & $<0.001$ \\
\hline & Period 2 & $11.5 \pm 1.8$ & $23.1 \pm 2.0$ & & \\
\hline \multirow{2}{*}{$\begin{array}{l}\text { Mean daily use of } \\
\text { ventilator (h/day) }\end{array}$} & Period 1 & $7.7 \pm 3.0$ & $10.8 \pm 4.7$ & $3.6(0.6$ to 6.7$)$ & 0.02 \\
\hline & Period 2 & $4.6 \pm 1.8$ & $8.9 \pm 6.4$ & & \\
\hline \multirow{2}{*}{$\begin{array}{l}\text { Number of days for } \\
\text { initiation of NPPV }\end{array}$} & Period 1 & $1.7 \pm 1.6$ & $4.6 \pm 1.9$ & 2.5 (1.3 to 3.7$)$ & 0.001 \\
\hline & Period 2 & $1.6 \pm 0.8$ & $3.7 \pm 1.0$ & & \\
\hline
\end{tabular}

Data are presented as mean \pm SD.

$\mathrm{Bf}$, breathing frequency; EPAP, expiratory positive airway pressure; HI-NPPV, high-intensity non-invasive positive pressure ventilation; IPAP, inspiratory positive airway pressure; LINPPV, low-intensity non-invasive positive pressure ventilation; PIP, peak inspiratory pressure; RR, respiratory rate; Vexp, expiratory volume; Vinsp, inspiratory volume; Vleak, leak volume.

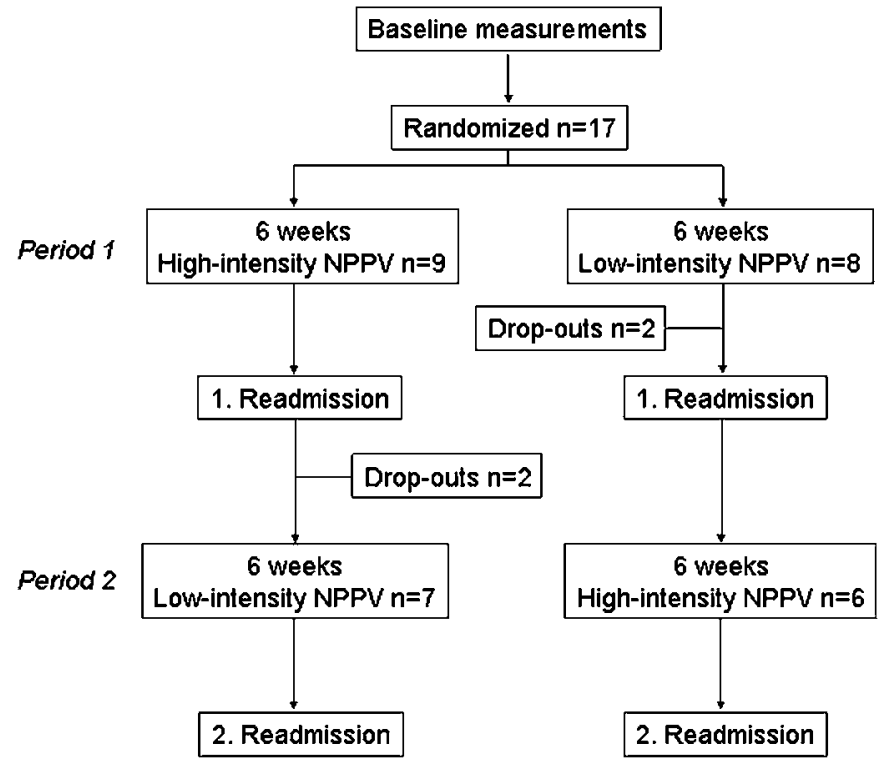

Figure 1 Trial profile. NPPV, non-invasive positive pressure ventilation.

There were no significant treatment effects between LI-NPPV and HI-NPPV in terms of SRI subscales (table 3). In particular, there was no difference in the subscale Attendant Symptoms and Sleep between the two NPPV modalities. With regard to all endpoints, no period or carryover effects were detected ( $p$ values of all tests for period effects $>0.05$ and $p$ values of tests for carryover effects $>0.1$ ), although the power for detection of carryover effects is low.

When comparing each treatment modality to baseline, HINPPV (but not LI-NPPV) resulted in significant improvements in

Table 2 Physiological parameters, exercise capability and healthrelated quality of life: high-intensity versus low-intensity NPPV

\begin{tabular}{|c|c|c|c|c|c|}
\hline & Period & LI-NPPV & HI-NPPV & $\begin{array}{l}\text { Difference between } \\
\text { treatments }(95 \% \mathrm{CI})\end{array}$ & $\begin{array}{l}p \\
\text { Value }\end{array}$ \\
\hline \multirow{2}{*}{$\begin{array}{l}\mathrm{Paco}_{2}(\mathrm{~mm} \mathrm{Hg}) \\
\text { mean nighttime }\end{array}$} & Period 1 & $56.6 \pm 9.2$ & $48.1 \pm 5.8$ & $-9.2(-13.7$ to -4.6$)$ & 0.001 \\
\hline & Period 2 & $57.2 \pm 7.7$ & $47.3 \pm 9.3$ & & \\
\hline \multirow{2}{*}{$\begin{array}{l}\mathrm{HCO}_{3}{ }^{-}(\mathrm{mmol} / \mathrm{l}) \\
\text { mean nighttime }\end{array}$} & Period 1 & $31.3 \pm 2.2$ & $28.9 \pm 1.9$ & $-1.9(-3.5$ to -0.3$)$ & 0.022 \\
\hline & Period 2 & $31.1 \pm 2.1$ & $29.6 \pm 2.6$ & & \\
\hline \multirow[t]{2}{*}{ TLC (I) } & Period 1 & $7.5 \pm 1.6$ & $7.6 \pm 1.5$ & $0.03(-0.52$ to 0.57$)$ & 0.91 \\
\hline & Period 2 & $7.4 \pm 0.8$ & $7.3 \pm 1.5$ & & \\
\hline \multirow[t]{2}{*}{$\mathrm{FEV}_{1}(\mathrm{I})$} & Period 1 & $0.64 \pm 0.11$ & $0.97 \pm 0.46$ & $0.05(-0.01$ to 0.11$)$ & 0.086 \\
\hline & Period 2 & $0.94 \pm 0.46$ & $0.70 \pm 0.17$ & & \\
\hline \multirow[t]{2}{*}{ VC (I) } & Period 1 & $1.82 \pm 0.23$ & $2.22 \pm 0.59$ & $0.08(-0.2$ to 0.36$)$ & 0.55 \\
\hline & Period 2 & $2.29 \pm 0.87$ & $2.00 \pm 0.18$ & & \\
\hline \multirow[t]{2}{*}{ 6MWD (m) } & Period 1 & $271 \pm 56$ & $302 \pm 163$ & $14(-42$ to 70$)$ & 0.58 \\
\hline & Period 2 & $308 \pm 145$ & $303 \pm 93$ & & \\
\hline \multirow[t]{2}{*}{ BDS after 6MWT } & Period 1 & $6.5 \pm 2.8$ & $3.4 \pm 3.6$ & $-2.4(-4.3$ to -0.4$)$ & 0.025 \\
\hline & Period 2 & $6.6 \pm 4.5$ & $5.0 \pm 2.9$ & & \\
\hline \multirow{2}{*}{$\begin{array}{l}\mathrm{PacO}_{2}(\mathrm{~mm} \mathrm{Hg}) \\
\text { mean daytime }\end{array}$} & Period 1 & $51.8 \pm 8.6$ & $50.1 \pm 3.0$ & $-2.9(-7.1$ to 1.4$)$ & 0.17 \\
\hline & Period 2 & $53.5 \pm 8.6$ & $49.6 \pm 6.7$ & & \\
\hline \multirow{2}{*}{$\begin{array}{l}\mathrm{HCO}_{3}{ }^{-}(\mathrm{mmol} / \mathrm{l}) \\
\text { mean daytime }\end{array}$} & Period 1 & $30.1 \pm 2.7$ & $29.4 \pm 1.3$ & $-1.0(-2.5$ to 0.5$)$ & 0.18 \\
\hline & Period 2 & $30.5 \pm 2.3$ & $29.3 \pm 2.3$ & & \\
\hline \multirow[t]{2}{*}{ PImax (kPa) } & Period 1 & $5.0 \pm 1.2$ & $6.4 \pm 3.0$ & $0.01(-0.65$ to 0.66$)$ & 0.99 \\
\hline & Period 2 & $5.3 \pm 1.9$ & $4.6 \pm 1.7$ & & \\
\hline \multirow[t]{2}{*}{ SRI-SS } & Period 1 & $60.3 \pm 12.9$ & $65.3 \pm 21.2$ & $-0.14(-4.9$ to 4.6$)$ & 0.95 \\
\hline & Period 2 & $65.3 \pm 23.1$ & $60.1 \pm 1 \backslash 0.3$ & & \\
\hline
\end{tabular}

Data are presented as mean \pm SD.

6MWD, 6-minute walking distance; 6MWT, 6-minute walking test; BDS, Borg dyspnoea scale; $\mathrm{FEV}_{1}$, forced expiratory volume in $1 \mathrm{~s}$; HI-NPPV, high-intensity non-invasive positive pressure ventilation; $\mathrm{HCO}_{3}{ }^{-}$, bicarbonate; LI-NPPV, low-intensity non-invasive positive pressure ventilation; $\mathrm{PaCO}_{2}$, arterial carbon dioxide tension; PImax, maximal inspiratory mouth occlusion pressure; SRI-SS, Severe Respiratory Insufficiency Questionnaire Summary Score; TLC, total lung capacity; VC, vital capacity. 


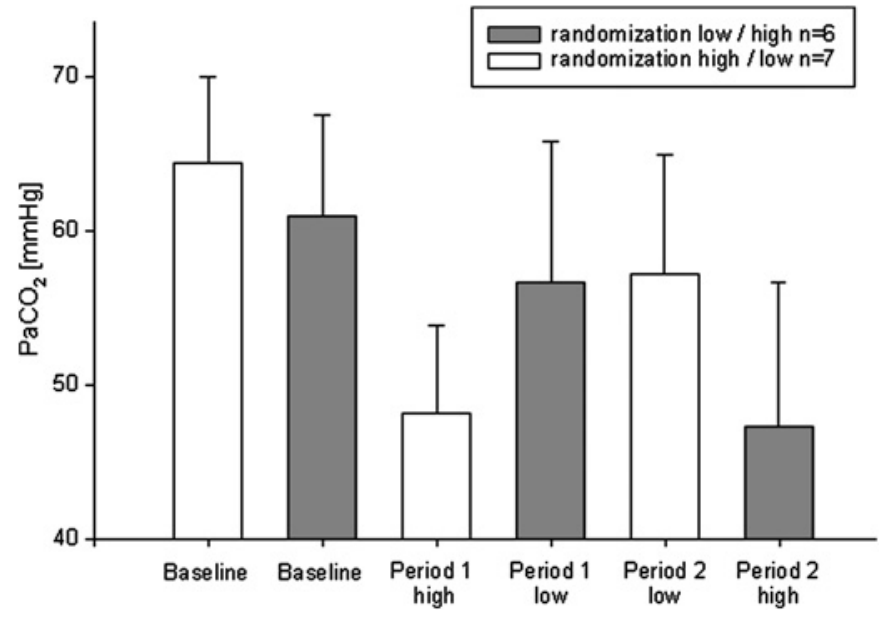

Figure 2 Nocturnal mean $\pm S D$ arterial carbon dioxide tension $\left(\mathrm{PaCO}_{2}\right)$ at baseline and at follow-up visits.

nocturnal and daytime $\mathrm{PacO}_{2}$, lung function, $\mathrm{BDS}$ following walking and Summary Scale of the SRI (table 4).

\section{DISCUSSION}

This is the first prospective randomised crossover study comparing two completely different modalities of NPPV for patients with severe chronic HRF due to COPD. The first modality used in the present study is based on NPPV in the assisted mode with relatively low IPAP, which was the most common mode used in previous RCTs of patients with $\mathrm{COPD}^{1-4}$; accordingly, the average IPAP in the present study was 15 mbar. This modality has been labelled LI-NPPV and differs from the novel approach of HI-NPPV ${ }^{7}{ }^{11-13}$ which uses a controlled mode of NPPV and higher IPAP of around 29 mbar in the present study.

Controlling nocturnal hypoventilation is of major clinical importance and has not been addressed by the majority of previous studies. ${ }^{8}$ In this regard, nocturnal $\mathrm{PacO}_{2}$ served as the primary outcome parameter in the present study. The main finding was that nocturnal hypoventilation is more efficaciously corrected when patients used HI-NPPV rather than LI-NPPV.

Table 3 Subscales of the Severe Respiratory Insufficiency (SRI) Questionnaire: high-intensity versus low-intensity NPPV

\begin{tabular}{llllll}
\hline & Period & LI-NPPV & HI-NPPV & $\begin{array}{l}\text { Difference between } \\
\text { treatments (95\% CI) }\end{array}$ & $\begin{array}{l}\text { p } \\
\text { Value }\end{array}$ \\
\hline SRI-RC & Period 1 & $56.3 \pm 14.0$ & $62.1 \pm 25.1$ & $0.6(-6.1$ to 7.3$)$ & 0.85 \\
& Period 2 & $61.6 \pm 25.3$ & $57.0 \pm 12.9$ & & \\
SRI-PF & Period 1 & $38.3 \pm 17.5$ & $43.5 \pm 31.4$ & $-1.5(-10.6$ to 7.6) & 0.71 \\
& Period 2 & $48.2 \pm 37.5$ & $40.0 \pm 19.7$ & & \\
SRI-AS & Period 1 & $66.4 \pm 15.5$ & $76.5 \pm 18.5$ & $-1.8(-5.8$ to 2.1) & 0.33 \\
& Period 2 & $81.6 \pm 17.8$ & $67.9 \pm 16.6$ & & \\
SRI-SR & Period 1 & $81.5 \pm 12.5$ & $80.4 \pm 14.0$ & $-2.3(-7.6$ to 3.0) & 0.36 \\
& Period 2 & $79.8 \pm 16.0$ & $76.3 \pm 11.5$ & & \\
SRI-AX & Period 1 & $51.0 \pm 10.8$ & $67.1 \pm 33.5$ & $4.7(-6.0$ to 15.4) & 0.35 \\
& Period 2 & $60.0 \pm 34.6$ & $53.3 \pm 11.6$ & & \\
SRI-WB & Period 1 & $67.8 \pm 9.2$ & $67.5 \pm 27.1$ & $-0.02(-10.0$ to 10.0) & 1.00 \\
& Period 2 & $68.3 \pm 20.1$ & $68.6 \pm 12.1$ & & \\
SRI-SF & Period 1 & $60.6 \pm 23.4$ & $59.8 \pm 25.6$ & $-0.6(-9.8$ to 8.5) & 0.89 \\
& Period 2 & $57.9 \pm 25.2$ & $57.5 \pm 16.5$ & & \\
\hline
\end{tabular}

Data are presented as mean $\pm S D$

AS, Attendant Symptoms and Sleep; AX, Anxiety; HI-NPPV, high-intensity non-invasive positive pressure ventilation; LI-NPPV, low-intensity non-invasive positive pressure ventilation; PF, Physical Functioning; RC, Respiratory Complaints; SF, Social Functioning; SR, Social Relationships; SRI, Severe Respiratory Insufficiency Questionnaire; WB, Psychological Well-Being.
Thereby, the mean treatment effect on nocturnal $\mathrm{PacO}_{2}$ was more than $9 \mathrm{~mm} \mathrm{Hg}$ in favour of HI-NPPV. This effect was due to the different ventilation strategies, as revealed by external pneumotachographic measurements. Specifically, HI-NPPV produced inspiratory volumes which were on average $325 \mathrm{ml}$ higher than those produced by LI-NPPV. As a consequence, expiratory volumes which reflect the minimal assured tidal volume ${ }^{27}$ were on average $95 \mathrm{ml}$ higher during HI-NPPV than LI-NPPV. Interestingly, there was no difference in the absolute values for respiratory rate. However, during LI-NPPV, patients had low back-up respiratory rates set by the ventilator, so they were forced to trigger most-if not all-of the breaths. This is in contrast to HI-NPPV, where the respiratory rates set by the ventilator and the actual measurements turned out almost identical values; these results indicate that the patient did indeed receive controlled ventilation during HI-NPPV. Since work of breathing is known to be significantly lower while on controlled than on assisted ventilation, ${ }^{28} \mathrm{HI}-\mathrm{NPPV}$, as used in the current setting, is not only superior in decreasing raised $\mathrm{Paco}_{2}$ levels in patients with COPD with severe chronic HRF, it is also likely to rest the respiratory muscles more efficiently. However, it remains unclear if the positive effects of HI-NPPV may be attributed to the ventilation mode, to the level of inspiratory pressures, to the breathing frequency or to a combination of these.

Table 4 Comparison of baseline and treatment for low-intensity NPPV $(n=13)$ and high-intensity NPPV $(n=15)$

\begin{tabular}{|c|c|c|c|c|}
\hline & Baseline & $\begin{array}{l}\text { After } 6 \text { weeks } \\
\text { of NPPV }\end{array}$ & Difference $(95 \%$ Cl) & $\begin{array}{l}p \\
\text { Value }\end{array}$ \\
\hline $\begin{array}{l}\text { LI-NPPV-Paco } 2 \\
01.00 \mathrm{~h}(\mathrm{~mm} \mathrm{Hg})^{*}\end{array}$ & $61.5 \pm 5.8$ & $58.0 \pm 9.4$ & $-3.6(-9.1$ to 2.0$)$ & 0.19 \\
\hline $\begin{array}{l}\text { HI-NPPV-Paco } \\
01.00 \mathrm{~h}(\mathrm{~mm} \mathrm{Hg})^{*}\end{array}$ & $63.6 \pm 7.7$ & $49.6 \pm 7.8$ & $-14.0(-18.5$ to -9.4$)$ & $<0.001$ \\
\hline $\begin{array}{l}\text { LI-NPPV-Paco } \\
12.00 \mathrm{~h}(\mathrm{~mm} \mathrm{Hg}) \dagger\end{array}$ & $56.4 \pm 5.8$ & $52.7 \pm 7.9$ & $-3.6(-8.9$ to 1.6$)$ & 0.16 \\
\hline $\begin{array}{l}\text { HI-NPPV-Paco } \\
12.00 \mathrm{~h}(\mathrm{~mm} \mathrm{Hg}) \dagger\end{array}$ & $58.0 \pm 7.6$ & $51.8 \pm 6.4$ & $-6.2(-9.5$ to -2.9$)$ & $<0.001$ \\
\hline $\begin{array}{l}\text { LI-NPPV-HCO }{ }_{3}^{-} \\
01.00 \mathrm{~h}\left(\mathrm{mmol} / \mathrm{l}^{*}\right.\end{array}$ & $33.4 \pm 2.8$ & $31.5 \pm 2.4$ & $-1.9(-4.5$ to 0.5$)$ & 0.11 \\
\hline $\begin{array}{l}\text { HI-NPPV- } \mathrm{HCO}_{3}{ }^{-} \\
01.00 \mathrm{~h}(\mathrm{mmol} / \mathrm{l})^{*}\end{array}$ & $34.3 \pm 3.6$ & $30.2 \pm 3.2$ & $-4.1(-5.8$ to -2.4$)$ & $<0.001$ \\
\hline $\begin{array}{l}\text { LI-NPPV-HCO }{ }_{3}^{-} \\
12.00 \mathrm{~h}(\mathrm{mmol} / \mathrm{l}) \dagger\end{array}$ & $32.6 \pm 2.7$ & $30.5 \pm 2.3$ & $-2.2(-4.5$ to 0.2$)$ & 0.07 \\
\hline $\begin{array}{l}\text { HI-NPPV- } \mathrm{HCO}_{3}{ }^{-} \\
12.00 \mathrm{~h}(\mathrm{mmol} / \mathrm{l}) \dagger\end{array}$ & $33.8 \pm 4.9$ & $30.4 \pm 3.6$ & $-3.4(-4.9$ to -1.9$)$ & $<0.001$ \\
\hline LI-NPPV-FEV 1 (I) & $0.76 \pm 0.29$ & $0.80 \pm 0.37$ & $0.04(-0.07$ to 0.16$)$ & 0.44 \\
\hline HI-NPPV-FEV 1 (I) & $0.74 \pm 0.29$ & $0.85 \pm 0.39$ & 0.11 (0.01 to 0.21$)$ & 0.037 \\
\hline LI-NPPV-VC (I) & $1.95 \pm 0.45$ & $2.07 \pm 0.68$ & $0.13(-0.17$ to 0.42$)$ & 0.37 \\
\hline HI-NPPV-VC (I) & $1.96 \pm 0.58$ & $2.14 \pm 0.62$ & $0.22(0.06$ to 0.39$)$ & 0.012 \\
\hline $\begin{array}{l}\text { LI-NPPV-BDS after } \\
\text { 6MWT‡ }\end{array}$ & $9(4 / 10)$ & $6(4 / 10)$ & & 0.55 \\
\hline $\begin{array}{l}\text { HI-NPPV-BDS after } \\
\text { 6MWT } \neq\end{array}$ & $9(4 / 10)$ & $4(3 / 5)$ & & 0.014 \\
\hline LI-NPPV-6MWD & $252 \pm 131$ & $291 \pm 111$ & $38.5(-2.7$ to 79.7$)$ & 0.065 \\
\hline HI-NPPV-6MWD & $264 \pm 129$ & $297 \pm 125$ & $32.9(-24.3$ to 90.1$)$ & 0.24 \\
\hline LI-NPPV-PImax (kPa) & $4.8 \pm 1.6$ & $5.1 \pm 1.5$ & $0.37(-0.59$ to 1.33$)$ & 0.41 \\
\hline HI-NPPV-PImax (kPa) & $5.0 \pm 2.3$ & $5.6 \pm 2.5$ & $0.53(-0.2$ to 1.3$)$ & 0.16 \\
\hline LI-NPPV-SRI-SS & $58.0 \pm 14.6$ & $63.2 \pm 18.9$ & $5.3(-0.42$ to 11.0$)$ & 0.066 \\
\hline HI-NPPV-SRI-SS & $55.8 \pm 15.5$ & $62.2 \pm 16.3$ & $6.4(1.5$ to 11.2$)$ & 0.014 \\
\hline
\end{tabular}

Data are presented as mean \pm SD unless otherwise stated.

6MWT, 6-minute walking test; BDS, Borg dyspnoea scale; $\mathrm{FEV}_{1}$, forced expiratory volume in $1 \mathrm{~s}$; HI-NPPV, high-intensity non-invasive positive pressure ventilation; $\mathrm{HCO}_{3}{ }^{-}$, bicarbonate; LI-NPPV, low-intensity non-invasive positive pressure ventilation; $\mathrm{Paco}_{2}$, arterial carbon dioxide tension; PImax, maximal inspiratory mouth occlusion pressure; SRI-SS, Severe Respiratory Insufficiency Questionnaire Summary Score; TLC, total lung capacity; VC, vital capacity.

*Blood gases taken during night time non-invasive ventilation.

†Blood gases taken under spontaneous breathing.

$¥$ Median values with IQR. 
The different physiology produced by the two treatment modalities has important clinical implications. First, there was a clear treatment effect on exercise-related dyspnoea in favour of HI-NPPV. Given that severe dyspnoea can underlie physical handicap and is well recognised as a prognostic marker in patients with advanced COPD, ${ }^{29}$ this finding is of major clinical importance. The crossover comparison analysis showed no significant differences in daytime $\mathrm{Paco}_{2}$, lung function, $6 \mathrm{MWD}$, PImax or the Summary Scale of the SRI; however, this study was not powered to detect differences in these outcome parameters. In contrast, when both modalities were compared with baseline, only HI-NPPV was associated with significant improvements in daytime $\mathrm{PacO}_{2}$ as well as in lung function and HROL as measured by the SRI. This again demonstrates that the superiority of HINPPV over LI-NPPV in improving clinical parameters is likely. It should be noted, however, that there was also a clear trend towards HROL improvements observed with LI-NPPV treatment. Nevertheless, further studies powered to address these outcome parameters are needed to verify these findings.

The observation in the present study of an improvement in HROL challenges the most recent study in which NPPV was associated with deteriorations in HROL. ${ }^{1}$ This discrepancy is presumably explained by the different methodology used for HROL assessment. In the study by McEvoy and co-workers, only generic questionnaires which were non-specific to both COPD and chronic respiratory failure revealed differences in $\mathrm{HROL}$ while the COPD-specific St George's Respiratory Questionnaire did not. ${ }^{1}$ In contrast, the present study applied the SRI, a questionnaire specifically designed to measure HROL in patients with COPD receiving long-term NPPV for the treatment of chronic HRF. ${ }^{24} 25$ In addition, other studies that used the SRI and other instruments specific for chronic respiratory failure also reported improvements in HROL. ${ }^{31213}$ We therefore still support the notion that HROL improves rather than deteriorates when long-term NPPV is administered to patients with COPD with chronic HRF.

Nevertheless, the findings reported in the present study and in previous investigations ${ }^{6} 7^{11-13}$ suggest that HI-NPPV provides a promising alternative to the conventional approach (LI-NPPV) in the treatment of chronic HRF that arises from COPD. The current authors therefore suggest that statements in the literature reporting that long-term NPPV has little or no clinical benefit for patients with COPD are premature and inconclusive, ${ }^{1-5} 30$ hence justifying the need for long-term RCTs that investigate the effects of HI-NPPV on long-term survival, symptom control, HROL and exacerbation frequency.

One might expect that HI-NPPV with controlled ventilation and high IPAP levels averaging 29 mbar would not be nearly as well tolerated as LI-NPPV with assisted ventilation and almost $50 \%$ lower IPAP levels. Interestingly, however, the opposite was observed to be true. Patients who received HI-NPPV spent an average of 3.6 additional hours per day on NPPV compared with the average time spent on LI-NPPV, thus indicating improved compliance with HI-NPPV. In addition, four patients could not tolerate LI-NPPV whereas all patients tolerated HI-NPPV. Moreover, previous long-term studies have shown that HI-NPPV was well tolerated over a period of years and produced long-term survival rates that were higher than historical cohorts. ${ }^{6}>11$ A recent study also indicated substantial HROL benefits after patients with COPD with chronic HRF were established on HINPPV. ${ }^{13}$ Finally, two studies have shown that patients were even able to walk during simultaneous HI-NPPV when the ventilator was programmed to the nocturnal settings with which the patients were already familiar; this resulted in improved oxygenation, ${ }^{16}{ }^{31}$ dyspnoea and walking distance. ${ }^{16}$ Therefore, there is now robust data to suggest that HI-NPPV is well tolerated and perhaps a better option than the already established approach of LI-NPPV.

There are, however, two disadvantages of HI-NPPV use that need to be addressed. First, patients required more days in hospital (2.5 days) to acclimatise to HI-NPPV compared with LINPPV, thus increasing costs. Second, pneumotachographic measurements revealed that leak volume was considerably higher in HI-NPPV than in LI-NPPV, with a mean difference of $226 \mathrm{ml}$, although this could also have accounted for expiratory leakage..$^{27}$ Nevertheless, this could have caused more side effects and impairments in sleep quality. The present study is therefore limited by the fact that side effects specifically related to leakage were not assessed, nor were measurements of sleep quality using polysomnography performed. However, there were clearly no reductions in HROL scores in HI-NPPV compared with LI-NPPV as assessed by both the Summary Scale and the subscales of the SRI. Thus, a major impact on subjective perception seems unlikely. In particular, the subscale scores of the SRI addressing subjective sleep disturbances were not worsened with HI-NPPV treatment. Nevertheless, other modes of NPPV such as those aimed at improving nocturnal hypoventilation in obesity hypoventilation syndrome-that is, average volume assured pressure support-showed trends of reduced sleep quality. ${ }^{32}{ }^{33}$ Further studies addressing subjective and objective sleep quality are therefore needed to evaluate the potential role of HI-NPPV in the treatment of chronic HRF due to COPD. Finally, pneumotachographic measurements of peak inspiratory pressures revealed lower values than actual settings, both during LI-NPPV and HI-NPPV. This appears to be mainly attributed to substantial leakage being present in this study when leak compensation capabilities of pressure-limited NPPV are exceeded, ${ }^{26} 2732$ but might also be due to pressure loss along the line of the circuit as pressure settings and measurements occurred at different sites. ${ }^{27}$

In conclusion, high-intensity NPPV using a controlled mode of ventilation with a mean inspiratory positive airway pressure of $29 \mathrm{mbar}$ is well tolerated by patients with COPD with severe chronic HRF. Furthermore, for controlling nocturnal hypoventilation, HI-NPPV was shown to be superior to the conventional and widely used form of low-intensity NPPV that uses assisted ventilation with mean inspiratory positive airway pressures of 15 mbar. This novel approach is also advantageous in improving important clinical parameters including dyspnoea during physical activity, lung function and HROL. High-intensity NPPV therefore offers a new and promising therapeutic option in the treatment of patients with COPD with chronic HRF. Based on the present results, further long-term RCTs are needed to determine whether high-intensity NPPV can also improve long-term survival.

Acknowledgements We thank Dr Sandra Dieni for helpful comments on the manuscript prior to submission.

Competing interests The study group received an open research grant from Breas Medical AB, Molnlycke, Sweden and from Respironics, Pittsburgh, Pennsylvania, USA This study was supported by Respironics, Pittsburgh, Pennsylvania, USA. Neither the study design, results, interpretation of the findings nor any other subject discussed in the submitted manuscript was dependent on support.

Ethics approval This study was conducted with the approval of the Institutional Review Board for Human Studies at the Albert-Ludwigs University, Freiburg, Germany and was performed in accordance with the ethical standards laid down in the Declaration of Helsinki. Informed, written consent was obtained from all subjects.

Provenance and peer review Not commissioned; externally peer reviewed.

\section{REFERENCES}

1. McEvoy RD, Pierce RJ, Hillman D, et al. Nocturnal non-invasive nasal ventilation in stable hypercapnic COPD: a randomised controlled trial. Thorax 2009;64:561-6. 
2. Casanova C, Celli BR, Tost L, et al. Long-term controlled trial of nocturnal nasal positive pressure ventilation in patients with severe COPD. Chest 2000;118:1582-90.

3. Clini E, Sturani C, Rossi A, et al. The Italian multicentre study on noninvasive ventilation in chronic obstructive pulmonary disease patients. Eur Respir J 2002;20:529-38.

4. Wijkstra PJ, Lacasse $Y$, Guyatt GH, et al. A meta-analysis of nocturnal noninvasive positive pressure ventilation in patients with stable COPD. Chest 2003:124:337-43.

5. Kolodziej MA, Jensen L, Rowe B, et al. Systematic review of noninvasive positive pressure ventilation in severe stable COPD. Eur Respir J 2007;30:293-306.

6. Windisch W, Kostic S, Dreher $\mathrm{M}$, et al. Outcome of patients with stable COPD receiving controlled noninvasive positive pressure ventilation aimed at a maximal reduction of $\mathrm{PaCO}_{2}$. Chest 2005;128:657-62.

7. Windisch W, Haenel M, Storre $\mathbf{J H}$, et al. High-intensity non-invasive positive pressure ventilation for stable hypercapnic COPD. Int J Med Sci 2009;6:72-6

8. Elliott MW. Domiciliary non-invasive ventilation in stable COPD? Thorax 2009;64:553-6.

9. Meecham Jones DJ, Paul EA, Jones PW, et al. Nasal pressure support ventilation plus oxygen compared with oxygen therapy alone in hypercapnic COPD. Am J Respir Crit Care Med 1995:152:538-44.

10. Diaz 0, Begin P, Andresen M, et al. Physiological and clinical effects of diurnal noninvasive ventilation in hypercapnic COPD. Eur Respir J 2005;26:1016-23.

11. Windisch W, Vogel $M$, Sorichter $S$, et al. Normocapnia during nIPPV in chronic hypercapnic COPD reduces subsequent spontaneous $\mathrm{PaCO}_{2}$. Respir Med 2002;96:572-9.

12. Windisch W, Dreher $\mathrm{M}$, Storre $\mathrm{JH}$, et al. Nocturnal non-invasive positive pressure ventilation: Physiological effects on spontaneous breathing. Respir Physiol Neurobiol 2006;150:251-60

13. Windisch W. Impact of home mechanical ventilation on health-related quality of life. Eur Respir J 2008;32:1328-36.

14. Budweiser S, Heinemann F, Meyer K, et al. Weight gain in cachectic COPD patients receiving noninvasive positive-pressure ventilation. Respir Care 2006:51:126-32.

15. Budweiser S, Jorres RA, Riedl T, et al. Predictors of survival in COPD patients with chronic hypercapnic respiratory failure receiving noninvasive home ventilation. Chest 2007:131:1650-8.

16. Dreher $\mathbf{M}$, Storre JH, Windisch W. Noninvasive ventilation during walking in patients with severe COPD: a randomised cross-over trial. Eur Respir J 2007;29:930-6.

17. Sutherland ER, Cherniack RM. Management of chronic obstructive pulmonary disease. N Engl J Med 2004;350:2689-97.

18. Rabe KF, Hurd S, Anzueto A, et al. Global strategy for the diagnosis, management, and prevention of chronic obstructive pulmonary disease: GOLD executive summary. Am J Respir Crit Care Med 2007;176:532-55.
19. Quanjer PH, Tammeling GJ, Cotes JE, et al. Lung volumes and forced ventilatory flows. Report working party standardization of lung function tests, European Community for Steel and Coal. Official statement of the European Respiratory Society. Eur Respir J Supp/ 1993;16:5-40.

20. Windisch W, Hennings E, Sorichter $S$, et al. Peak or plateau maximal inspiratory mouth pressure: which is best? Eur Respir J 2004;23:708-13.

21. Butland RJ, Pang J, Gross ER, et al. Two-, six-, and 12-minute walking tests in respiratory disease. BMJ (Clin Res Ed) 1982;284:1607-8.

22. Anon. ATS statement: guidelines for the six-minute walk test. Am J Respir Crit Care Med 2002;166:111-7.

23. Borg GA. Psychophysical bases of perceived exertion. Med Sci Sports Exerc 1982:14:377-81.

24. Windisch W, Freidel K, Schucher B, et al. The severe respiratory insufficiency (SRI) questionnaire: a specific measure of health-related quality of life in patients receiving home mechanical ventilation. J Clin Epidemiol 2003;56:752-9.

25. Windisch W, Budweiser $S$, Heinemann $F$, et al. The severe respiratory insufficiency questionnaire was valid for COPD patients with severe chronic respiratory failure. J Clin Epidemiol 2008;61:848-53.

26. Windisch W, Storre JH, Sorichter S, et al. Comparison of volume- and pressurelimited NPPV at night: a prospective randomized cross-over trial. Respir Med 2005;99:52-9.

27. Storre JH, Bohm P, Dreher M, et al. Clinical impact of leak compensation during noninvasive ventilation. Respir Med 2009;103:1477-83.

28. Nilsestuen J0, Hargett KD. Using ventilator graphics to identify patient-ventilator asynchrony. Respir Care 2005;50:202-34.

29. Celli BR, Cote CG, Marin JM, et al. The body-mass index, airflow obstruction, dyspnea, and exercise capacity index in chronic obstructive pulmonary disease. N Eng/ J Med 2004:350:1005-12.

30. Wijkstra PJ. Non-invasive positive pressure ventilation (NIPPV) in stable patients with chronic obstructive pulmonary disease (COPD). Respir Med 2003;97:1086-93.

31. Dreher $\mathbf{M}$, Doncheva E, Schwoerer A et al. Preserving oxygenation during walking in severe chronic obstructive pulmonary disease: noninvasive ventilation versus oxygen therapy. Respiration 2009; 78:154-60.

32. Storre JH, Seuthe B, Fiechter $\mathrm{R}$, et al. Average volume-assured pressure support in obesity hypoventilation: a randomized crossover trial. Chest 2006;130:815-21.

33. Janssens $\mathbf{J}$, Metzger $M$, Sforza $E$. Impact of volume targeting on efficacy of bi-level non-invasive ventilation and sleep in obesity-hypoventilation. Respir Med 2009;103:165-72. 